DigitALCOMMONS @WAYNESTATE -
Michigan Journal of Counseling:

Research, Theory and Practice

Volume 33 | Issue 1

Article 3

$8-1-2005$

\title{
Group Supervision: A Review of Practices and Models in Training
}

Jeremy M. Linton

Indiana University South Bend

Follow this and additional works at: https://digitalcommons.wayne.edu/mijoc

\section{Recommended Citation}

Linton, J. M. (2005). Group Supervision: A Review of Practices and Models in Training, Dimensions of Counseling, 33(1), 10-16. doi: $10.22237 / \mathrm{mijoc} / 1122854520$

This Article is brought to you for free and open access by the Open Access Journals at DigitalCommons@WayneState. It has been accepted for inclusion in Michigan Journal of Counseling: Research, Theory and Practice by an authorized editor of DigitalCommons@WayneState. 


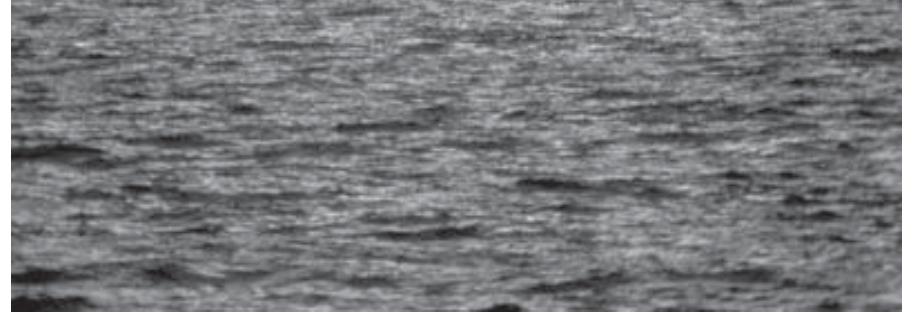

\section{Group Supervision: A Review of Practices and Models in Training}

\section{Jeremy M. Linton}

Indiana University South Bend

Jeremy M. Linton, Ph.D., is an Assistant Professor of Counseling

and Human Services in the School of Education at Indiana

University South Bend.
Group supervision is an often used modality of supervision for post-degree and practicing counselors. Despite its wide use, practicing supervisors in the community receive little to no training in group supervision methods and practices. This article is intended to review several key practices and models of group supervision. In total, two practice considerations for forming supervision groups and five models of group supervision are outlined. The article concludes with a brief integration of these models and several suggestions for practice are offered. roup supervision is a widely used modality of supervision for post-degree counselors seeking licensure as well as experienced practitioners in the field (Altfeld \& Bernard, 1997; Borders, 1991; Carroll, 1996; Goodyear \& Nelson, 1997; Holloway \& Johnston, 1985; Proctor, 2000; Prieto, 1996, 1998; Proctor \& Inskipp, 2001; Riva \& Cornish, 1995; Stoltenberg, McNeill, \& Delworth, 1998). Despite its wide use, few supervisors have received adequate training in group supervision techniques and practices. This lack of training for supervisors is noticeable in community settings where fully-licensed counselors often provide supervision to post-degree practitioners seeking licensure. Because few states have set training requirements for the practice of supervision, virtually any fully-licensed counselor can provide supervision without a demonstrated knowledge or skill set. Much of the supervision provided to postdegree and experienced counselors seems to be conducted in a group format.

The delivery of group supervision services by uninformed, untrained, and perhaps unprepared supervisors is problematic and raises ethical concerns for 
the practice of supervision.

Untrained or unqualified delivery of group counseling services to clients, for example, would undoubtedly be considered outside the realm of ethical practice. The purpose of this article, therefore, is to introduce practicing supervisors in community settings to several models of group supervision. In total, two considerations for the formation of supervision groups and five models of group supervision are reviewed. This review is not intended to serve as a detailed training in group supervision. Rather, it is anticipated that this brief review will provide a general understanding of several models of group supervision and motivate supervisors to engage in a more detailed exploration of this understudied topic. The article concludes with an integration of these models and several general suggestions for practice are offered.

\section{Considerations for Starting Supervision Groups}

Similar to psychotherapy groups, it is important to consider several aspects of group work when forming supervision groups. Bernard and Goodyear (1998) and Locket (2001) have identified the benefits of establishing a group structure and the use of supervision contracts as integral parts of successful group experiences. These are discussed below.

\section{Establishing a Structure}

Bernard and Goodyear (1998) described the establishment of ground rules and group structure as pivotal tasks in forming and facilitating functional supervision groups. "Although group structure and ground rules may seem a mundane topic, they can significantly influence the group process" (p. 120). Establishing ground rules and structure includes such tasks as identifying meeting places, frequency of meetings and attendance issues, how group members are to interact (e.g., empathically,

collaboratively), the role of the supervisor (e.g., facilitator, process expert, teacher), case presentation and clinical questioning norms, and confidentiality issues. Bernard and Goodyear state that establishing these parameters at the beginning of group is the first step in creating a collaborative, cooperative, and encouraging group atmosphere.
In constructing group norms, supervisors may find it beneficial to facilitate the development of cohesion, universality, and inclusion early in the life of a supervision group (Bernard \& Goodyear, 1998; Linton, 2003). This may entail taking time during early sessions to employ structured or unstructured group building exercises. Additionally, supervisors should guard against corrosive group processes such as competition, conflict, and scapegoating during early group meetings (Linton, 2003; Linton \& Hedstrom, in press). This may involve inhibiting any conflict relating to the supervisor discreetly early in the group's life.

\section{Group Supervision Contracts}

Lockett (2001) identified the development of group contracts as a useful technique when forming supervision groups. She stated that negotiating contracts with supervisees allows supervisors to explicitly establish group rules and norms, identify the purpose of, and expectations for, supervision meetings, and offer protection to counselor-client and supervisorsupervisee relationships. According to Lockett, effective group contracts identify the following: (a) the supervisor's and supervisees' responsibilities to the group members, (b) negotiated boundaries, (c) place and frequency of meetings, $(\mathrm{d})$ attendance and fee issues (if applicable), (e) case presentation guidelines, and (f) explanations of confidentiality and "duty to care" issues. The contract should also offer supervisees the "opportunity to develop a safe learning climate" (p. 156). Lockett suggested that the group supervision contract be revisited often in order to assure that each group member's needs are being met and to maintain focus during group meetings.

\section{Group Supervision Models}

The following five supervision models are exemplars for group supervision, representing both structured and unstructured formats: (a) Structured Group Supervision (Wilbur, Roberts-Wilbur, Morris, Betz, \& Hart, 1991), (b) Systemic Peer Group Supervision (Borders, 1991), (c) a case presentation model (McAullife, 1992), (d) an analytic model (Rosenthal, 1999), and (e) Experiential Group 
Supervision (Altfeld, 1999; Altfeld \& Bernard, 1997). Suggestions for practice are included in the discussion of each model.

\section{Structured Group Supervision}

Wilbur et al. (1991) created the Structured Group Supervision (SGS) model in response to the perceived lack of research and practice directives in the area of group supervision. They stated that "the [SGS] model attempts to strengthen the link between group supervision and its justified use in counselor training programs" (p. 91). As a structured model of group supervision, SGS provides a format for case presentations and specifies how supervisees and supervisors are to interact and provide feedback.

The SGS model is a five-phase process designed to assist supervisees in focusing their case presentations during group supervision. During group meetings, supervisees discuss a single case for approximately one hour. In Phase One of the model, a group member makes a request for assistance to the group. Then, in the questioning and identification of focus phase (Phase Two), group members clarify the request for assistance and gather further information about the problem. During Phase Three, group members provide feedback pertinent to the presenter's request. This feedback is provided in an "I statement" format such as, "If this were my client I wouldÖ" In Phase Four, the supervisee responds as to whether the feedback was helpful. In the optional fifth phase, the preceding four phases are processed.

According to Wilbur et al. (1991), the SGS format is "structured for the active involvement and participation of all group members" (p. 92). A pilot study of the SGS model suggested that participants made significant gains in skill and personal development as compared to supervisees engaged in non-SGS supervision groups (Wilbur, Roberts-Wilbur, Hart, Morris, \& Betz, 1994). In the author's experience as a group supervisor, supervisees have often reported that they benefit a great deal from the manner in which feedback is provided in Phase Three. When feedback is provided in the form of "I statements," supervisees state that they feel less defensive and more open to suggestions and feedback from their supervisor and peers.

\section{Systemic Peer Group Supervision}

Borders (1991) developed the Systemic Peer Group Supervision (SPGS) model to address unproductive and problematic aspects of peer group supervision approaches. She noted that in supervision groups, "peers may be overly supportive and prone to giving advice, and [that] the group may have difficulty staying on task" (p. 248). Borders stated that in order for supervision groups to be effective, "group meetings need an organizational structure" (p. 248).

The SPGS model offers a structure for group supervision meetings. It was created to address the following goals:

(a) to ensure that all group members are involved in the supervision process; (b) to help members give focused, objective feedback; (c) to give particular attention to the development of cognitive counseling skills; (d) to be adaptable for groups of novice and / or experienced counselors; (e) to provide a framework for supervising individual, group, and family counseling sessions; (f) to teach an approach that counselors can internalize for self monitoring; and (g) to provide a systemic procedure that can be employed by novice and experienced supervisors (p. 248).

The model was developed through applied practice in the training of novice and experienced counselors.

Procedurally, the SPGS model was designed for use with three to six counselors/ supervisees and one trained supervisor. During SPGS meetings, supervisors guide group members through a series of six steps. In Step One, a supervisee identifies questions and asks the group for specific feedback about her performance in a videotaped segment of a counseling session. Then, in Step Two, group members are assigned tasks, roles, or perspectives for responding to the presenter's questions. These may include observing body language or a particular counseling skill (task), taking another role, such as that of the counselor or a significant other of client (role), responding to the session via a particular theoretical orientation (perspective), or using a metaphor to describe the counseling process.

In Step Three of the model, the supervisee shows the videotaped segment of counseling mentioned in Step one. Group members then present feedback from their particular tasks, roles, or perspectives (Step Four). This feedback is directed at the supervisee's specific questions offered in Step One. Then, in Step Five, the supervisor facilitates this feedback discussion. Lastly, in Step Six, the supervisor summarizes the feedback presented by the group and facilitates the presenter's evaluation of the feedback. Throughout all six steps, the supervisor's role is to keep the group on task and engage all group members in the discussion.

Critical to the success of the SPGS model is the Step Two process of assigning tasks, roles, or perspectives. Borders (1991) noted that neophyte counselors are often "selffocused," "overly aware of their every move," and "assume that the client's report is the only truth about the problem situation" (p. 249). When other group members respond from these alternate tasks, roles, or perspectives, 
supervisees are assisted in reducing self-focus, viewing the case through "a different set of eyes," and broadening their view of the client and counseling session. For instance, if a group member provides feedback from the role of the client's spouse, the presenter's vision of how other persons respond to the client's behavior may be enhanced. Role taking also allows group members to provide challenging and constructive feedback in a less threatening manner.

Research has indicated that supervisees taking part in SPGS supervision groups found it informative and valuable to their professional development (Werstlein \& Borders, 1997). Supervisees in SPGS groups also have also reported decreases in confusion and anxiety, clarification of goals, and increased confidence as a result of taking part in a SPGS group (Starling \& Baker, 2000). These findings offer preliminary verification regarding the effectiveness of this model.

\section{Case Presentation Model}

McAuliffe (1992) offered a Case Presentation Model (CPM) of group supervision. This structured model of group supervision is described as most appropriate for use with practicing professionals rather than counselor-trainees.

Procedurally, the CPM was designed for use with a small group of experienced counselors led by an experienced supervisor. During each group meeting, one group member presents a single case, in detail, and discusses it with the group.

The format for case presentations in the CPM is a fourstage process described by the acronym SOAP. In the $S$ stage, the presenter describes the subjective aspects of the case, including why the case was selected and specific issues to be addressed by group members. Then, in the $O$ stage, objective information is provided, such as the client's background, psychological testing data, and a summary of counseling work to date. Next, in the $A$ stage the presenter provides a provisional diagnostic impression. Finally, in the $P$ stage, the presenter outlines her current treatment plan. McAuliffe (1992) noted that the four-stage $S O A P$ process assists counselors in taking responsibility for their clinical decisions.

After the SOAP presentation is completed, group members and the supervisor "ask questions, suggest further information to be gathered, and propose treatment possibilities" (McAuliffe, 1992, p. 168). During this discussion, the supervisor uses reflection and probing iven that most

counselor-trainees

and practicing professionals

experience group

supervision during

practicum,

internship, and in

post-degree

settings, the lack of

training received by

those who provide

group supervision is

problematic (Bernard

\& Goodyear, 1998;

Borders, 1991; Riva

\& Cornish, 1995). skills to keep the group dialogue on track. At the end of the session, the presenter gives feedback as to whether the group's feedback and suggestions were helpful. During the process, the supervisor assumes the role of process facilitator and expert, he/she models professional behavior, diagnostic expertise, and case presentation skills. McAuliffe stated that having an expert supervisor can prevent the likelihood of the "uninformed leading the uninformed," as may happen without the presence of a supervisor (p. 165).

In implementing the CPM model, McAuliffe (1992) suggested that group supervision be explicitly distinguished from other types of staff meetings. Group supervision time, McAuliffe stated, should be reserved for "intensive clinical analysis" of cases (p. 170). McAuliffe also suggested that group norms should be established, which may include the use of group contracts. Finally, each group meeting should entail some degree of peer facilitation and group members should routinely process their work together.

To date, no empirical research has been conducted on the effectiveness the CPM. However, counselor trainees supervised using the CPM have indicated through informal feedback that they appreciate the SOAP structure for case presentations and state that the format assists them in organizing their thoughts and clinical impressions in more efficient and effective ways.

\section{Analytic Model}

Rosenthal (1999) developed the Analytic Model (AM) of group supervision. The goals of this unstructured model are to assist supervisees in understanding their clients, monitoring their own emotional reactions, and dealing with a range of instinctual forces. As the name suggests, the model is rooted in analytical thought but participation in AM groups is not limited to counselors who adhere to the analytical model of clinical practice.

During AM meetings, supervisors assist supervisees in resolving countertransference resistance, a key impediment to clinical success. The resolution of countertransference resistance involves helping group members to identify their emotional reactions to clients and resolve any problematic emotional reactions. Supervisors using the AM also engage in emotional demonstration, a practice that involves the display of effective analytic skills and techniques. It is thought that 
through this demonstration, supervisees can learn important counseling skills. To accomplish these tasks, Rosenthal (1999) stated that the group leader must establish a "fully accepting group climate in which group members will feel free to express all feelings evoked in them without fear of criticism or censure" (p. 203).

Rosenthal (1999) suggested 90-minute supervision meetings with six to 15 group members. She stated that a contract is offered to a new group member at the outset of supervision. The contract conveys that members are to:

present problems and concerns they are encountering in working with their [clients], are to take their share of time, are to help each other do the same, and are to hold in confidence whatever is discussed in the group (p. 207).

Aside from this, Rosenthal stated that no other formal structure is offered to the group. During group discussions, the supervisor assumes the roles of process commentator, observer of resistance (including nonparticipation of a group member), and facilitator. Group discussions, then, consist of a free flowing dialogue about clients' and counselors' emotional reactions and countertransference issues. It is expected that supervisees come to group meetings prepared to discuss cases and are not to monopolize entire group sessions. A review of the literature revealed no empirical investigations of Rosenthal's analytic model.

\section{Experiential Group Supervision}

Altfeld (1999) developed the Experiential Group Model (EGM), also an unstructured model of group supervision. The EGM, which is analytic in nature, "involves using supervisory group members' interactions as the matrix out of which supervision occurs" (Altfeld, 1999, p. 237). Altfeld noted that the EGM is conceptually different than models that include case presentations as the main focus of supervision time. He stated that several problems are evident in case presentation approaches, including possible shame and guilt reactions in the presenting therapists when critical responses are presented, and feeling overwhelmed by the large amount of feedback offered by peers. Additionally, Altfeld suggested that some issues brought to group meetings may not be of a technical nature or due to insufficient knowledge, which is often the focus of case presentation models. Rather, Altfeld contended that some issues may be related to emotional countertransference blocks. As such, Altfeld suggested that the resolution of these blocks requires a counteremotional experience on the part of the therapist. Experiential group supervision was developed to address these issues.
Altfeld (1999) described the key theoretical concepts of the model as emphasizing a "holding environment, group as a container, the frame, parallel process, projective identification, reassimilation, [and] the general concept of guided unconscious communication" (p. 387). The EGM emphasizes concepts from "object relations theory and from group-as-a-whole dynamics" (p. 239). The essential underlying assumption of the model is that cases described during group supervision elicit both conscious and unconscious reactions in group members. When these reactions are discussed, important emotional issues can be raised and examined.

Procedurally, the EGM begins with a group member describing a clinical case. During this description, group members are instructed to "take note of whatever images, fantasies, feelings, memories, associations, and / or bodily sensations they experience while listening to the material presented" (Altfeld, 1999, p. 240). Group members are instructed to share these associations with the group, no matter how personal, bizarre, idiosyncratic, inconsequential, or unrelated they seem. Prior to the sharing of these associations, the supervisor stresses the notion that each is likely related to the case in some way, and is a "piece of the puzzle" that will help to resolve countertransference issues.

Tantamount to the success of this approach is the supervisory task of helping group members to follow the instructions. As Altfeld (1999) noted, "clinicians are prone to giving opinions, formulations, clinical insights, and so on" (p. 241). When this occurs, Altfeld offered several suggestions for getting the discussion back on track. For example, the supervisor may respond, "Yes that could be rightÔ but did you have any feelings or associations related to what the presenter was saying?" This type of supervisor response re-inducts the group members into the experiential group model.

Altfeld (1999) suggested that the EGM may not be appropriate for use with beginning therapists. He stated that neophyte counselors do not have the background necessary for participation in such a group, and the employment of these techniques may result in increased supervision resistance and anxiety. Additionally, Altfeld stated that the model should not be viewed as an "all or nothing proposition," and that it can be equally effective if parts are borrowed and incorporated into other forms of group supervision (p. 252). To date, no research has been conducted on the experiential model of group supervision.

\section{Considerations for Practice}

Given that most counselor-trainees and practicing professionals experience group supervision during practicum, internship, and in post-degree settings, the 
lack of training received by those who provide group supervision is problematic (Bernard \& Goodyear, 1998; Borders, 1991; Riva \& Cornish, 1995). Each of the models delineated here provides a well thought-out framework for the practice of group supervision.

When selecting a format for supervision groups, it is strongly suggested that practicing supervisors consider the developmental and experiential levels of the counselors in their groups. As Stoltenberg et al. (1998) suggest, supervisees at different levels of professional development have different supervision needs and goals. The literature on group supervision suggests that structured models of group supervision (e.g., Wilbur et al., 1991) may be better suited for counselor-trainees while unstructured models may be better for seasoned professionals (Borders, 1991; McAuliffe, 1992). The use of sequences and structure in structured models may help to lessen neophyte counselors' anxiety levels, whereas experienced practitioners may be best served when allowed to set their own agenda for group meetings.

Additionally, recent research on group supervision supports the contention that establishing a supportive group climate and cohesion are important in group supervision. In studies by Christensen and Kline (2001), Linton (2003), Linton and Hedstrom (in press), Starling and Baker (2000), Walter and Young (1999), and Werstlein and Borders (1997), supervisees stated that the supportive and cohesive atmosphere in their groups was important to their professional development. Supervisees in these studies also stated that this type of group climate assisted them in becoming more honest and interactive with their peers and motivated them to become invested in the professional development of their peers. Based on these research findings, it is therefore recommended that practicing supervisors work diligently to create a warm and cohesive climate in their supervision groups. Several of the models outline here address this practice.

Empirical and anecdotal evidence also suggests that peer interactions are valuable and important to supervisee development (Christensen \& Kline, 2001; Linton, 2003; Linton \& Hedstrom, in press; Starling \& Baker, 2000; Walter \& Young, 1999; Werstlein \& Borders, 1997) and peer interactions are usually noted as important justifications for the use of group supervision (Bernard \& Goodyear, 1998; Proctor, 2000). This is not to imply, however, that supervisees do not value feedback received from their supervisors (Linton, 2003). Based on recent studies of group supervision, it is recommended that he literature on

group supervision

suggests that

structured models of

group supervision

(e.g., Wilbur ef al.,

1991) may be

better suited for

counselor-trainees

while unstructured

models may be

better for seasoned

professionals

(Borders, 1991;

McAuliffe, 1992). supervisors create group norms and rules that encourage supervisee interactions and feedback, while also interjecting their own comments when appropriate (Borders, 1991; Christensen \& Kline, 2001; Linton, 2003; Starling \& Baker, 2000; Walter \& Young, 1999; Werstlein \& Borders, 1997). This type of group climate will help to assure that group members receive a wide range of feedback from multiple perspectives and may assist supervisees to conceptualize clinical cases from standpoints other than their personal worldview. Each of the models, particularly the structured models, offers mechanisms for achieving this goal.

\section{Conclusion}

In conclusion, this article introduces practicing supervisors to several issues related to group supervision practice in order to stimulate professional discourse and investigation to this often used method of training. As models and empirically validated techniques for group supervision continue to be developed, it will be important to keep practicing supervisors informed of advances in the field. Quality training, as well as professional communication through journals and other forms of dissemination, will be critical in these efforts. Ultimately, increased training in group supervision methods will translate to improved, ethical, and competent counseling practices.

\section{References}

Altfeld, D. (1999). An experiential group model for psychotherapy supervision. International Journal of Group Psychotherapy, 49(2), 237253.

Altfeld, D., \& Bernard, H. (1997). An experiential group model for group psychotherapy supervision. In C. Watkins (Ed.), Handbook of psychotherapy supervision. New York: John Wiley and Sons.

Bernard, J., \& Goodyear, R. (1998). Fundamentals of clinical supervision (2nd ed.). Boston, MA: Allyn and Bacon.

Borders, L. (1991). A systemic approach to peer group supervision. Journal of Counseling and Development, 69, 248-252.

Carroll, M. (1996). Counseling supervision: Theory, skills and practice. London: Cassell.

Christensen, T., \& Kline, W. (2001). The qualitative exploration of process-sensitive peer group supervision. Journal for Specialists in Group Work, 26(1), 81-99.

Goodyear, R., \& Nelson, M. (1997). The major formats of psychotherapy supervision. In C. Watkins (Ed.) Handbook of psychotherapy supervision. New York: John Wiley and Sons.

Holloway, E., \& Johnston, R. (1985). Group supervision: Widely practiced but poorly understood. Counselor Education and Supervision, 24, 332-340.

Linton, J. (2003). A preliminary qualitative investigation of group 
processes in group supervision: Perspectives of master's level practicum students. Journal for Specialists in Group Work, 28(3), 215226.

Linton, J. \& Hedstrom, S. (in press). An Exploratory Qualitative Investigation of Group Processes in Group Supervision: Perceptions of Master's Level Practicum Students. Journal for Specialists in Group Work.

Lockett, M. (2001). The responsibilities of group supervisors. In S. Wheeler \& D. King (Eds.), Supervising counselors: Issues of responsibility. Worldwide: Sage.

McAuliffe, G. (1992). A case presentation approach to group supervision for community college counselors. Counselor Education and Supervision, 31, 163-174.

Prieto, L. (1996). Group supervision: Still widely practiced but poorly understood. Counselor Education and Supervision, 35, 295-307.

Prieto, L. (1998). Practicum class supervision in CACREP-accredited counselor training programs: A national survey. Counselor Education and Supervision, 38, 113-123.

Proctor, B. (2000). Group supervision: A guide to creative practice. Worldwide: Sage.

Proctor, B., \& Inskipp, F. (2001) Group supervision. In J. Scaife (Ed.), Supervision in the mental health professions: A practitioner's guide. Philadelphia, PA: Brunner-Routledge.
Riva, M., \& Cornish, A. (1995). Group supervision practices at psychology predoctoral internship programs: A national survey. Professional Psychology: Research and Practice, 26(5), 523-525.

Rosenthal, L. (1999). Group supervision of groups: A modern analytic perspective. International Journal of Group Psychotherapy, 49(2), 197213.

Starling, P., \& Baker, S. (2000). Structured peer group practicum supervision: Supervisees' perceptions of supervision theory. Counselor Education and Supervision, 39, 162-176.

Stoltenberg, C., McNeill, B., \& Delworth, U. (1998). IDM supervision: An integrated developmental model for supervising counselors and therapists. San Francisco, CA: Jossey-Bass.

Walter, C., \& Young, T. (1999). Combining individual and group supervision in educating for the social work profession. The Clinical Supervisor, 18(2), 73-89.

Werstlein, P., \& Borders, L. (1997). Group process variables in group supervision. Journal for Specialists in Group Work, 22(2), 120-136.

Wilbur, M., Roberts-Wilbur, J., Morris, J., Betz, R., \& Hart, G. (1991). Structured group supervision: Theory into practice. Journal for Specialists in Group Work, 16(2), 91-100. 